\title{
Population-ecological analysis of Rutilus Rutilus Aralensis Berg in Tuzkan lake, Uzbekistan
}

\author{
$S$. Nomozov $^{1}, B$. Jumaboev $^{2}, O$. Abralov $^{2}$, and B. Kamilov, ${ }^{3, *}$ \\ ${ }^{1}$ Institute of Zoology, Uzbek Academy of Sciences, Bogishamol str., 232b, Tashkent, Uzbekistan \\ ${ }^{2}$ Navoi State Pedagogical Institute, Ibn Sino str., Navoi, Uzbekistan \\ ${ }^{3}$ Tashkent State Agrarian University, University str., 2, Tashkent province, Uzbekistan, 100140
}

\begin{abstract}
Population-ecological analysis of Aral roach (Rutilus rutilus aralensis) was conducted in Tuzkan lake of Aydar-Arnasay lake system in Uzbekistan. In the Aydar-Arnasay lake system, it was analyzed the age structure, body weight, 19 morphometric and 5 meristematic indicators of 158 fish specimens caught in Tuzkan Lake in January and February 2020. The main selected indicators as a result of statistical analysis are: arithmetic mean; error rate; indicators of variability of morphometric and morpho-physiological signs; and variable asymmetry of meristem indicators. Statistical evaluation was conducted to determine the reliability of the survey results. Some features of the morpho-physiological state of the studied population were identified, which were explained by naturalclimatic features, as well as anthropogenic impact on the water basin.
\end{abstract}

\section{Introduction}

In modern biology, the population is considered as an elementary unit of the evolutionary process, the efficient use of nature on a scientific basis, the protection of biological resources and, consequently, sustainable development $[1,2]$. Based on these concepts, the population can be considered as an elementary unit of complex environmental monitoring. The above, however, substantiates the relevance of conducting ecological and biological research to study the populations of different living organisms in different ecological-geographical conditions and gradients of anthropogenic influences $[1,3]$. Defining the scope of intra-species variability of different character groups serves as a basis for the development and adaptation of regional norms and criteria for assessing environmental quality indicators [3].

One of the most important environmental problems today is the study and protection of freshwater ecosystems [4]. Rational use of freshwater resources and conservation of biodiversity of aquatic organisms by analyzing the state of hydroecosystems, assessing the impact of wastewater on water body biota cannot be done without knowledge of the population-ecological characteristics of many common species of invertebrates and vertebrates $[4,5]$. Fish populations and communities are one of the main components of

* Corresponding author: b.kamilov@tdau.uz 
aquatic biota, as fish live long enough to replenish the food chain in the water and require special attention due to their ability to accumulate harmful substances [6, 7].

The lack of information in the literature on the current state of the Aydar-Arnasay lake system (AALS) basins, including the population status of fish species in the AALS [8,9], not only increases the relevance of this work, but also the fact that the Aral Sea in Tuzkan makes study and analysis necessary.

\section{Materials and methods}

The source of this research is the biological measurements of fish caught from AALS Tuzkan Lake in April and May 2020.

We caught the fish using nets with a grid size of $30 \mathrm{~mm}$ and a length of 60 meters from April 29 to May 5, 2020, and biologically analyzed 158 roach. Weight of caught fish up to $5 \mathrm{mg}$ accuracy using analytical scales; morphological parameters were measured to 0.02 mm using a caliper (Figure 1) $[8,11]$.

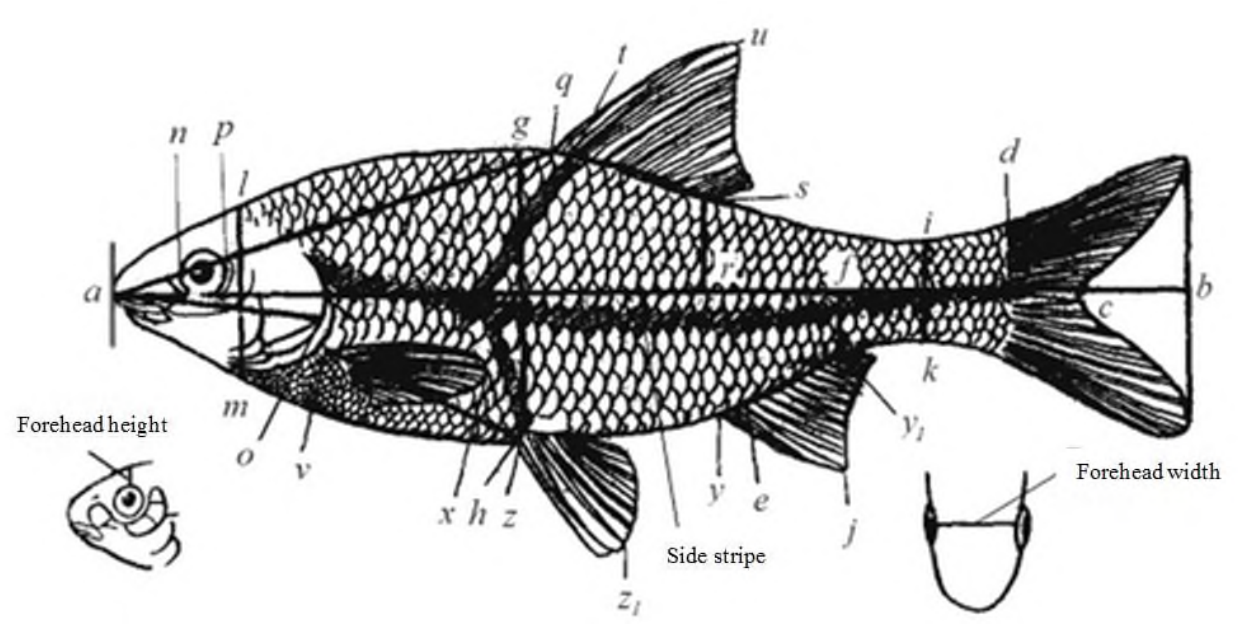

Fig. 1. Measurement diagram of carp fish

$C$ - tail fin; $D$ - shoulder strainer; $A$ - anal filter; $P$ - chest strainer; $V$ - abdominal strainer; ad or l-C wing length; ao - length of the head; an - length of the beak; $n p$ - eye diameter (horizontal); po - the back of the head; lm - height of the head; w - width of forehead; gh highest part of the body; ik - the lowest part of the body; aq - antedorsal distance; rd postdorsal distance; $f d$ - length of the tail base; qs - length of the base $D$; tu $-D$ maximum length; yyl - length of the base A; ej - A maximum length; vx - length of $P$; zz1 - length of $V$, vy-distance between $P$ and $A$; and $z u$-distance between $V$ and $A$.

For each indicator: arithmetic mean $(\ddot{\mathrm{x}})$, variance $\left(\boldsymbol{\sigma}^{2}\right)$, standard deviation $(\boldsymbol{\sigma})$, arithmetic mean error $(\mathrm{m})$ and coefficient of variability $(\mathrm{Cn} \%)$ were determined $[1,10]$. The age of the fish was determined by studying the coin preparations prepared by magnifying them $10 \times 20$ times in a Cole Parmer binocular based on the annual rings counted (Figure 2). 


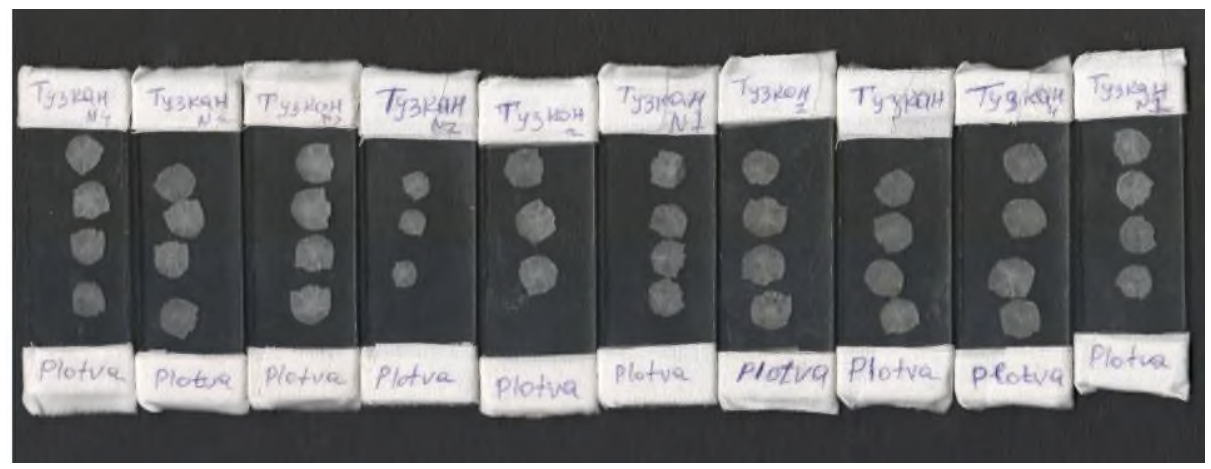

Fig. 2. A preparation made from the scales of carp fish

To assess the water quality of Lake Tuzkan, the five meristematic features of the Aral Sea crucian: the number of rays in the breast filter; the number of rays in the abdominal filter; the number of gills; number of laryngeal teeth; the number of coins in the side line was calculated as fluctuating asymmetry indicators [7].

To do this, the appearance of a particular character on both sides of the fish's body was taken into account. The value of the fluctuated asymmetry is calculated from the value of the variance between the parties, and the value of the variance between the parties is not less than zero (strict asymmetry), but arises from the appearance of some differences between the selected fish. Assessing lake water quality was carried out according to the scale proposed by V.M. Zakharov [9]. All calculations were performed in Microsoft Excel computer program.

\section{Results and discussion}

By analyzing the affiliation criteria of the fish caught, it was determined that they were Aral roach (Rutilus rutilus aralensis Berg, 1916).

The results of ecological-biological analysis showed that the number of coins on the side line of the studied fish varies from 39 to 44 ; the teeth of the larynx have a series of formulas in the form of 6-5, 5-5, 6-4, the number of thoracic and abdominal fins does not change, and is 12 and 9, respectively. The results of morpho-physiological analysis showed that the average weight of fish was $89.7 \pm 0.03 \mathrm{~g}$. The predominance of female fish was observed when the sex ratio was studied (according to the Student's criterion, it was 5.51 at $\mathrm{R}<0.001$ and the proportion of females was $63 \pm 9 \%$. Hermaphrodite fish samples were not observed in the studied population. However, it has been observed that for this population there is an early sexual maturation $[3,9,10]$, In our samples taken from Tuzkan Lake, the gonads of 2-year-old female fish are in the IV stage of sexual maturation, i.e. found to be sexually mature.

In the literature, as the length and weight of a fish's body increase, so does its elasticity [4]. Alternatively, this figure may vary in juveniles of the same size, which may be explained by differences in the habitat conditions and developmental period of some juveniles.

In the studied population, the absolute fertility rates were found to be lower than in other water bodies. Although the absolute fertility rate in the roach population in Tuzkan has increased, the decrease in the relative fertility rate in the older representatives is explained by the relative inconvenience of the watershed ecosystem. With the increase in body weight and the decrease in fertility, the increase in fish length is negligible, and the 
energy of the nutrients is used primarily to build up reserves and ensure the survival of the fish, and only then is it used for reproduction.

When analyzing the variability feature of the characters, it was shown that most of the characters did not exceed the normal range of the variability coefficient (Table 1). The minimum variability coefficient (3.3\%) was observed at the antidorsal distance (white), and the maximum variability coefficient was observed at the eye diameter (np, 11.1\%).

Table 1. Morphometric features of the Aral Sea roach in Lake Tuzkan

\begin{tabular}{|c|c|c|c|c|c|c|c|c|c|}
\hline$\#$ & Codes & $\mathbf{n}$ & $\mathbf{m i n}$ & $\mathbf{m a x}$ & $\ddot{\mathbf{x}}$ & $\mathbf{M}$ & $\boldsymbol{\sigma}^{2}$ & $\boldsymbol{\sigma}$ & $\mathbf{C v \%}$ \\
\hline 1 & $a d$ or $l$ & 158 & 130 & 181 & 159.3 & 1.25 & 123.7 & 11.1 & 7.0 \\
\hline 2 & $a o$ & 158 & 30 & 46 & 39.8 & 0.32 & 8.1 & 2.8 & 7.2 \\
\hline \multicolumn{7}{|c|}{ Relative to scales. \% } \\
\hline 3 & $a n$ & 158 & 5.9 & 8 & 6.8 & 0.04 & 0.1 & 0.4 & 5.3 \\
\hline 4 & $n p$ & 158 & 4.7 & 7 & 5.5 & 0.07 & 0.4 & 0.6 & 10.8 \\
\hline 5 & $p o$ & 158 & 8.8 & 14 & 12.7 & 0.10 & 0.7 & 0.9 & 6.8 \\
\hline 6 & $a o$ & 158 & 21.9 & 28 & 25.0 & 0.11 & 0.9 & 0.9 & 3.8 \\
\hline 7 & $l m$ & 158 & 16.0 & 19 & 17.5 & 0.11 & 1.0 & 1.0 & 5.7 \\
\hline 8 & $w$ & 158 & 8.2 & 13 & 9.2 & 0.09 & 0.7 & 0.8 & 9.0 \\
\hline 9 & $g h$ & 158 & 30.1 & 35 & 32.1 & 0.13 & 1.4 & 1.2 & 3.7 \\
\hline 10 & $i k$ & 158 & 10.2 & 15 & 11.1 & 0.08 & 0.5 & 0.7 & 6.3 \\
\hline 11 & $a q$ & 158 & 48.2 & 54 & 51.2 & 0.19 & 2.8 & 1.7 & 3.3 \\
\hline 12 & $r d$ & 158 & 34.9 & 43 & 38.8 & 0.19 & 3.0 & 1.7 & 4.4 \\
\hline 13 & $f d$ & 158 & 16.2 & 22 & 19.2 & 0.14 & 1.6 & 1.3 & 6.5 \\
\hline 14 & $q s$ & 158 & 13.8 & 17 & 15.5 & 0.09 & 0.6 & 0.8 & 5.0 \\
\hline 15 & $t u$ & 158 & 19.6 & 25 & 22.4 & 0.15 & 1.7 & 1.3 & 5.8 \\
\hline 16 & $y y l$ & 158 & 11.0 & 20 & 13.3 & 0.14 & 1.7 & 1.3 & 9.7 \\
\hline 17 & $e j$ & 158 & 11.8 & 16 & 13.7 & 0.10 & 0.9 & 0.9 & 6.7 \\
\hline 18 & $v x$ & 158 & 17.2 & 21 & 18.9 & 0.10 & 0.8 & 0.9 & 4.6 \\
\hline 19 & $z z l$ & 158 & 15.8 & 21 & 17.9 & 0.12 & 1.1 & 1.0 & 5.7 \\
\hline 20 & $v z$ & 158 & 25.3 & 29 & 27.3 & 0.15 & 1.7 & 1.3 & 4.8 \\
\hline 21 & $z y$ & 158 & 21.6 & 28 & 24.4 & 0.17 & 2.3 & 1.5 & 6.2 \\
\hline & & & & Relative to head. \% & & \\
\hline
\end{tabular}




\begin{tabular}{|c|c|c|c|c|c|c|c|c|c|}
\hline$\#$ & Codes & $\mathbf{n}$ & $\min$ & $\mathbf{m a x}$ & $\ddot{\mathbf{x}}$ & $\mathbf{M}$ & $\boldsymbol{\sigma}^{\mathbf{2}}$ & $\boldsymbol{\sigma}$ & $\mathbf{C v} \%$ \\
\hline 22 & an & 158 & 23.8 & 33 & 27.8 & 0.18 & 2.6 & 1.6 & 5.8 \\
\hline 23 & $n p$ & 158 & 19.0 & 31 & 22.4 & 0.28 & 6.2 & 2.5 & 11.1 \\
\hline 24 & $w$ & 158 & 31.0 & 51 & 37.4 & 0.44 & 15.3 & 3.9 & 10.5 \\
\hline
\end{tabular}

As a result of the analysis of binary meristical signs, fluctuated asymmetry was observed on two signs: the number of laryngeal teeth and the number of coins in the lateral line, and only the mean difference between the parties in terms of the number of laryngeal teeth was statistically significant $(\mathrm{t}=2.45, \mathrm{R}<0.05)$. The asymmetry coefficient for this sign was $12.77 \%$. This, in turn, suggests that the homeoresis of the studied populations is stable, which can be described as "relatively clean" according to the results of the assessment of lake water quality in the scoring system.

\section{Conclusion}

The population of roach in Lake Tuzkan has a number of unique ecological-biological (female dominance, early maturation, low individual fertility, age-related relative fertility decline) and morpho-physiological (average body mass, decreased body length growth) characteristics of the water basin conditions, including adaptation to biological pollution and exposure to agricultural organic waste.

The low variability of morpho-physiological markers and the low fluctuating asymmetry of meristem markers indicate the stability of population homeoresis and indicate that the level of organic pollution of Lake Tuzkan does not exceed the critical amount.

\section{References}

1. Y. Abdullaev, Theoretics of statistics, 170-189 (2002)

2. A. A. Ivanov, Fish Physiology, 269 (Mir Press, Moscow, 2003)

3. A. YU. Levykh, G. G. Puznina, Bulletin of the Samara Scientific Center 14(3), 608611 (2012)

4. T. V. Salikhov, B. G. Kamilov, A. K. Atadjanov, Fish of Uzbekistan, 258 (Chinor ENK Press, Tashkent, 2001)

5. B. A. Levin, E. P. Simonov, O. A. Ermakov, M. A. Levina, E. A. Interesova, O. M. Kovalchuk, D. A. Vekhov, Hydrobiologia 788(1), 33-46 (2017)

6. N. V. Aladin, T. Chida, Y. S. Chuikov, Z. K. Ermakhanov, Y. Kawabata, J. Kubota, V. F. Zaitzev, ournal of Oceanology and Limnology 36(6), 2061-2084 (2018)

7. N. V. Aladin, V. I. Gontar, L. V. Zhakova, I. S. Plotnikov, A. O. Smurov, P. Rzymski, P. Klimaszyk, Environmental Science and Pollution Research 26(3), 2228-2237 (2019)

8. R. Kulmatov, A. Taylakov, S. Khasanov, Environmental Science and Pollution Research, 1-11 (2021)

9. N. S. Mamilov, F. T. Amirbekova, S. E. Sharakhmetov, S. N. Sapargalieva, F. K. Khabibullin, D. K. Bekkozhaeva, Bulletin of KazNU 82(1), 156-165 (2020)

10. N. SH. Mamilov, D. K. Bekkozhayeva, Eurasian Journal of Ecology 52(3), 112-122 (2018) 
11. M. A. Yuldashev, T. V. Salikhov, B. G. Kamilov, Fish of Uzbekistan, 191 (Gold-Print Nashr Press, Tashkent, 2018) 